\title{
Marie-Soledad Rodríguez (ed.), Le Fantastique dans le cinéma espagnol contemporain, Presses Sorbonne Nouvelle, París, 2011. ISBN: 978-2-87854-501-2
}

Aunque ya en los años noventa el cine fantástico español comenzó a cobrar un papel esencial en estudios fundacionales sobre el cine de género europeo como el acometido por Cathal Tohill y Peter Tombs en Inmoral Tales. Sex and Horror Cinema in Europe (1995), no ha sido hasta los primeros años del siglo XXI cuando ha empezado a gozar de la atención crítica y académica que durante años se le ha negado. En la actualidad, autores e investigadores como Antonio Lázaro-Reboll, Andrew Willis, Núria Triana-Toribio o Joan Hawkins, entre otros, han ayudado a configurar una serie de protocolos de lectura para el género, derribando los prejuicios con que la misma crítica española desactivó el interés académico en estas películas durante los años setenta, implantando los estudios culturales (cuya tardía aceptación en España es uno de los probables motivos por los que nuestro cine fantástico haya tardado tanto tiempo en ser abordado), tomando conceptos como el paracinema como un punto de partida pertinente, $y$, en definitiva, desafiando el canon crítico tan hostil no sólo al terror o al fantástico facturados en el país, sino, en general, a cualquier género de los denominados populares. De entre estos autores, sin embargo, resultaba patente la ausencia de una aportación francesa de peso, teniendo en cuenta la fecunda tradición de su escuela en lo que al estudio del cine fantástico se refiere (Gérard Lenne, Jean-Louis Leutrat). El volumen colectivo Le fantastique dans le cinéma espagnol contemporain, publicado en 2011, viene, en cierto modo, a cubrir este vacío.

La compilación está editada y coordinada por la profesora Marie-Soledad Rodríguez, y contempla un total de once artículos, más una introducción de la misma editora, que abarcan una diversidad de aspectos del cine fantástico producido en España durante las últimas cuatro décadas. A saber: «Le fantastique comme principe de composition: une poétique du récit cinématographique» (Antoine Gaudin); «Le fantastique espagnol, une approche historique du genre» (Sergi Ramos Alquezar); «Un inconnu dans la maison: l'enfant dans ¿Quién puede matar a un niño?» (Bénédicte Brémard); «Quand Daninsky rencontre Satomi, ou le croisement des genres dans La bestia y la espada mágica (Jacinto Molina, 1983)»; «Le fantastique métaphorique ou les frontières du genre. Nunca es tarde (Armiñán, 1977) et Feroz (Gutiérrez Aragón, 1984)» (Marie-Soledad Rodríguez); «El día de la bestia (1995) de Álex de la Iglesia, comédie esperpéntica 
fantastique» (Delphine Chambolle); «Le fantôme espagnol, un rapport conflictuel au temps» (Sergio Ramos Alquezar); «Traces du gothique anglo-saxon dans Les Autres (2001) d'Alejandro Amenábar et Fragile (2005) de Jaume Balagueró» (Pamela Ellayah); «Porosité du conte de fées: Le labyrinthe de Pan (2006) de Guillermo del Toro, entre merveilleux et fantastique» (Gwenaël Tison); «Herméneutique du genre et problématique gender: héroïnes du cinéma d' horreur espagnol contemporain» (Antoine Gaudin); «NO-DO (2009) d' Elio Quiroga, REC (2007) et REC 2 (2009) de Paco Plaza et Jaume Balagueró: métadiscours et regards sur la société» (Marie-Soledad Rodríguez).

Llama la atención, en primer lugar, el carácter ecléctico de las películas y los temas seleccionados: aunque estos respetan en su orden cronológico los ciclos del cine fantástico español aceptados ya casi como una convención por quienes se aproximan a su estudio (a grandes rasgos, un largo periodo de relativa sequía hasta los años sesenta, una etapa de explosión hacia el final del franquismo, otro periodo de sequía y productos directos al vídeo durante los ochenta, y, finalmente, el resurgir del género de la mano de una nueva generación de cineastas a mediados de los noventa), los artículos no abordan específicamente los hitos del género. Esto es debido a que el libro acota su corpus entre 1974 y 2009, es decir, que evita, precisamente, los años en que se concentró el grueso del denominado fantaterror español, entre 1968 y 1975. Tales fechas propi- cian, por ejemplo, que se aborde ¿Quién puede matar a un niño? (Narciso Ibáñez Serrador, 1976) en vez de La residencia (Narciso Ibáñez Serrador, 1969), a pesar de que la influencia de este último título en el género durante los años siguientes a su estreno es, con probabilidad, más determinante que el primero. Propicia igualmente que a la hora de abordar la obra de una figura capital como Paul Naschy / Jacinto Molina, se escoja un título sui generis en su filmografía como es La bestia y la espada mágica (Paul Naschy, 1983), frente a películas más emblemáticas como $\mathrm{La}$ noche de Walpurgis (León Klimovsky, 1971) o La marca del hombre lobo (Enrique López Eguiluz, 1968). Las fechas escogidas son también el motivo por el que resulta notoria la ausencia de un cineasta como Jesús Franco, cuyas películas en los años sesenta y primera mitad de los setenta resultan, a pesar de su carácter estrictamente personal, esenciales en la implantación y configuración del imaginario fantaterrorífico español. Esta libertad de planteamientos, en suma, confiere a Le fantastique dans le cinéma espagnol contemporain una singularidad que no sólo le permite abordar películas poco estudiadas por sí mismas, como las que se acaban de mencionar, sino que aporta también una serie de temas relativamente desatendidos por el estudio de esta cinematografía: el fantasma, la heroína-materna o la tensión entre la tradición gótica anglosajona y el fantástico español.

Se echa en falta, sin embargo, aprovechando esta heterogeneidad de enfo- 
ques, un estudio específico que profundice en el vínculo que el cine fantástico español mantiene con la tradición cultural de España, a pesar de que a lo largo del libro se mencionan corrientes como el esperpento (muy especialmente en el artículo dedicado a El día de la bestia). Incluso se llega a hablar de la falta de una verdadera tradición literaria fantástica española ( $p$. 11), cuando, por ejemplo, los trabajos del profesor Roas (en especial De la maravilla al horror. Los inicios de lo fantástico en la cultura española, 2006, y La sombra del cuervo. Edgar Allan Poe y la literatura fantástica española del siglo XIX, 2011) han determinado que no se trata tanto de una ausencia como de un rechazo de la misma por parte de cierto canon crítico literario, concentrado sobre todo en el siglo XIX. Esta, en cualquier caso, es una carencia que empieza a ser relativamente habitual en los estudios sobre el tema, y que requiere ya de una investigación en concreto que rastree los lazos pictóricos, literarios y, en general, culturales de España con el cine de género producido a lo largo de su historia.

Así, Le fantastique dans le cinéma espagnol contemporain encuentra sus mejores aportaciones cuanto más específicos son los temas que aborda: en el artículo «Herméneutique du genre et problématique gender: héroïnes du cinéma d’horreur espagnol contemporain», que consigue trazar un vínculo temático y un subtexto común en la representación de la maternidad por parte de los nuevos cineastas fantásticos españoles, o en «NO-DO (2009) d' Elio Quiroga, REC (2007) et REC 2 (2009) de Paco Plaza et Jaume Balagueró: métadiscours et regards sur la société», donde se aborda la obra de esos tres directores desde una perspectiva sorprendentemente poco frecuentada en este campo: la de las estrategias narrativas estrictamente audiovisuales.

El volumen ofrece de esta manera una alternativa (aunque sería más acertado decir un complemento) a las aproximaciones historiográficas al cine fantástico español más heterodoxas, revelando que su estudio es aún un campo relativamente nuevo, y que todavía quedan importantes huecos que llenar. Muy especialmente, estos huecos parecen concernir a la última generación de cineastas especializados en el género (no existe ningún estudio específico sobre ellos), a la que el libro, de forma significativa, dedica casi la mitad de sus artículos.

Rubén SÁnchez Trigos Universidad Rey Juan Carlos ruben.sanchez.trigos@urjc.es

(c) $($ ) $(9)$ 